\title{
Escutar vozes e falar em línguas*
}

\section{Berenice Bento**}

O livro De corpos e travessias: uma antropologia de corpos e afetos, de Pedro Paulo Gomes Pereira (Annablume, 2014) discute paradoxos e dilemas em torno da vida e da morte mediante uma polifonia de vozes/silêncios e de línguas. O que é a morte para uma comunidade indígena? Como o saber/poder médico define que há vida em um corpo? E no meio do caminho, na travessia, tinha uma mulher que não bebia água. Como prescrever soro caseiro para uma comunidade que tem uma leitura diferente do funcionamento do corpo e sua relação com a água? É preciso falar "línguas", entender a cultura como um idioma e escutar as múltiplas vozes dos sujeitos que povoam nossas pesquisas considerando os sentidos que conferem às suas vidas como complexos sistemas analíticos, conforme aponta Pereira.

De corpos e travessias é definido pelo autor como um "livro experiência". Foi sendo escrito, revisto, revisitado, no compasso da própria travessia de vida do autor, ao longo de uma década. Ao todo são sete artigos organizados em três partes. De um capítulo ao outro temos a oportunidade de escutar o pesquisador dialogando com outras vozes que ele põe em cena.

Limite, tensão, conflito, disputa, limiar, desconfiança, são algumas das palavras que o autor utiliza sem economia para 1) interpretar a vida em uma comunidade de portadores de HIV em Brasília, 2) os dilemas dos profissionais de saúde em suas relações com comunidades indígenas, 3) as relações de verdade estabelecidas em torna da aids $e$ as novas formas de

\footnotetext{
* Recebida para publicação em 28 de maio de 2014, aceita em 25 de junho de 2015. Resenha do livro Pereira, Pedro Paulo Gomes. De corpos e travessias: uma antropologia de corpos e afetos. Editora Annablume. Coleção Queer, 2014.

*** Professora do Departamento de Ciências Sociais da UFRN, Natal, RN, Brasil. berenice.bento1@gmail.com
} 
biossocialidade na Espanha estruturadas por um grupo de dissidentes da aids, 4) a leitura generificada que faz dos cronotopos dos jornais, 5) os corpos e as tecnologias de gêneros, os desafios da tradução cultural, 6) o alcance e o limite de teorias gringas para explicar contextos sociais múltiplos, travestis que ressignificam o assujeitamento. As questões que se seguem são reverberações provocadas pela leitura do livro De corpos $e$ travessias.

\section{Teoria-falatório}

No capítulo Queer nos trópicos, Pereira problematiza a relação entre produção e reprodução do conhecimento. $\mathrm{O}$ que pode uma teoria? Qual o alcance de um conceito como "biopoder"? Como as teorias viajam e chegam a destinos diversos? $\mathrm{Na}$ divisão internacional do conhecimento os habitantes dos trópicos estariam destinados a aplicar as teorias formuladas na Europa e nos Estados Unidos? Padecemos de um "primitivismo intelectual" (Fanon apud Macey, 2000) que nos impede de construir grandes e abstratos sistemas explicativos para o funcionamento da vida?

As provocações do autor sobre como nos relacionamos com as teorias formuladas na Europa e Estados Unidos são fundamentais. Contudo, reconhecer o caráter provinciano e local de teóricos que se lançaram ao mundo como grandes intérpretes de contextos diversos, como faz Pedro Paulo, é também apontar que o desejo subjacente ao pensamento colonizador só se efetiva porque encontra morada cômoda nos pensamentos colonizados. Como romper a linha de reprodução do pensamento colonizado? Como produzir curtos-circuitos?

Para além de questões mais objetivas, como por exemplo, a política de citação, sugiro que deveríamos começar reconhecendo que padecemos de certa "teoria-falatório". O conceito de falatório aqui é pirateado de Martin Heiddegger (2002). O filósofo buscando compreender a existência do ser no mundo, dirá que passamos a conhecer o mundo a nossa volta pela linguagem $e$ 
que ela não se configura apenas como um veículo de transmissão de informação, mas como o modo no qual se manifesta o próprio existir humano. $O$ falatório, $\mathrm{O}$ ser tornando-se na e pela linguagem, defini-se como o contrário de uma apropriação originária do que se fala. É o repetir e passar adiante a fala sem uma reflexão do que se diz ou porque se diz. É um falar reiterado sem nada dizer de novo, um falar sem conteúdo original cujo conteúdo já é previamente conhecido.

$\mathrm{O}$ falatório norteia primariamente a nossa compreensão sobre o mundo. Tal compreensão é sempre pré-existente, ou seja, nos deixamos levar pelo discurso instituído pelos outros, $e$ isso faz com que a nossa existência seja fundamentada na concepção extraída do senso comum, segundo Heiddegger (2002). No falatório torna-se difícil discernir entre o que foi conquistado à custa de esforço original, analítico, resultado da crítica e o que se apreendeu de maneira curiosa e ambígua, a partir do que já se falava e se escrevia a respeito.

Embora Heiddegger localize o falatório como dimensão da vida cotidiana, acredito que no mundo acadêmico somos mais falatório e menos pensamento autêntico. Para interromper a circularidade do escutar-passar adiante a fala vazia, o autor afirma que a saída estaria na arte e na ciência. Diria que há muito falatório na ciência, principalmente quando se acredita que teorias que falam de realidades específicas, locais, possam dar conta de contextos múltiplos. Conforme apontou Pereira, "descontextualizar [esses] corpos e almas seria proceder a um tipo de violência epistemológica que atua retirando aquilo que é mais caro para os sujeitos envolvidos, desprezando suas invenções $e$ formas de agir" (Pereira, 2014:195). Esse talvez seja o efeito mais perverso da teoria-falatório: não enxergar singularidades, fissuras, não escutar as vozes dos outros. A "alteridade" só teria sentido mediante o encaixe do pensamento do outro no esquema analítico previamente definido pelo/a pesquisador/a. Ou seja, na teoria-falatório não é possível escutar as outras vozes e o exercício de compreender as alteridades fica vazio. 
Para se contrapor à teoria-falatório é necessário pensar o pensamento nos marcos da autenticidade. $\mathrm{O}$ que seria um pensamento autêntico? Acredito que a primeira premissa de um pensamento não colonizado seria desconfiar de teorias universalistas, de teóricos/as que olham o mundo como um sistema integrado. E essa desconstrução marca toda a urdidura narrativa De corpos e travessias, interrompendo a linha de reprodução e pondo em suspeição teorias e autores/as de países colonizadores. A cada capítulo nos deparamos com curtoscircuitos.

Um dos curtos-circuitos provocados por Pedro Paulo é sua estratégia de se relacionar epistemologicamente com as ideias de seus interlocutores como potentes formulares de conceitos. E assim, vemos surgir diante de nós a Cida, uma travesti, mineira, tímida e viajada, que confere sentido à sua vida mediante um conjunto complexo de valores do candomblé e que acionou sofisticadas tecnologias de gênero para construção do seu corpo feminino. Em contrapartida, o autor nos apresenta a fala de Beatriz Preciado, uma filósofa que ao abrir a boca e falar a primeira frase em francês, de imediato, sabemos que ela não é francesa, negando o próprio desejo da filósofa, que afirma transitar com a mesma fluidez entre três idiomas e, ao mesmo tempo, se propõe a interpretar o funcionamento desse mundo do qual ela é cidadã. Cida e Beatriz, duas filósofas que manejam teorias complexas.

Uma segunda estratégia para escaparmos da tentação da teoria-falatório seria fazermos perguntas imaginárias aos/às autores/as, mesmo sabendo que jamais serão respondidas. Por que Preciado, sujeito universal, teórica dos descontentes de gênero e das sexualidades dissidentes, não fala das perseguições das pessoas trans tanto na França quanto na Espanha? Por que as mulheres de seu pueblo na Espanha são consideradas "suas cachorras" (Preciado, 2008)? Na apologia da autoadministração da testosterona e na valorização de atributos masculinos, o que 
Preciado estaria propondo seria um retorno ao isomorfismo? ${ }^{1}$ Por que Foucault nunca se pronunciou (até onde minhas pesquisas me levaram) sobre a carnificina que os franceses fizeram na Argélia durante a Guerra da Independência Argelina (entre os anos de 1954 e 1962)? Conforma aponta Pereira,

Menos que inventariar as escassas referências à questão colonial [Foucault, Agamben, Rabinow, Esposito] nesses autores, talvez seja mais produtivo perceber esse silêncio vinculado ao envolvimento deles com seus contextos socioculturais; esse silêncio sendo atribuído aos limites da própria imersão nos dilemas da modernidade ocidental (2014:94)

Compreender que os/as autores/as estão intimamente vinculados/os aos seus quadros sócio-histórico-cultural, contextualizando suas produções intelectuais como produtos locais, seria outro curto-circuito no pensamento colonizador. Concordo com o autor quando afirma que não se trata de fazer boicotes às teorias gringas, mas entender que os conceitos que nascem com pretensões universais são fundamentalmente narrativas analíticas e "histórias particulares, locais, provinciais" (Pereira, 2014:94), com o mesmo valor interpretativo que as formulações de Cida.

\section{Infantilização e abjeção}

Em 1998, Pedro Paulo etnografou a comunidade Fraternidade, localizada nas proximidades de Brasília que abrigava pessoas que eram portadoras de HIV, quase todos expresidiários. A população dessa instituição era de 102 adultos e 50 crianças e funcionava com base na caridade. A dona do espaço

\footnotetext{
${ }^{1}$ Como se sabe, no isomorfismo não existe diferença de sexo, mas de gênero e o masculino seria a expressão dos corpos com maior grau de perfeição (força, vitalidade, energia, racionalidade). São basicamente os atributos masculinos que são valorizados em Testo Yonqui (Preciado, 2008).
} 
exigia ser chamada de tia Janaína, a exemplo das professoras de crianças na fase de alfabetização. A aparente familiaridade que o tratamento anuncia desaparece quando o autor descreve que o modus operandi da instituição estava assentado na díade delito \& castigo.

Desconfio que essa forma de estruturar as relações internas à instituição revela configurações mais densas da cultura nacional. Há um primeiro nível de relacionamento, a camada aparente, na qual tudo se passa como se as relações fossem acordadas, simétricas, quase familiares e, ao mesmo tempo, uma aversão aos conflitos. Essa seria a camada da vida social que Sérgio Buarque de Holanda (2009) nomeou em sua psicologia social de "cordialidade", a marca maior de distinção da nossa cultura em relação às outras. Mas essa é a camada superficial das relações sociais, aquela que produziu e congelou o estereótipo do/a brasileiro/a para o mundo e que diz sermos um povo feliz, que recebe todos sem distinção de classe, raça ou gênero.

$\mathrm{Na}$ segunda camada veremos como essa cordialidade se efetiva nas relações com os diferentes. É possível aceitar e conviver com os negros se os negros se comportarem como eternos escravos, se não exigirem políticas de reparação via ações afirmativas. É possível se relacionar cordialmente com os gays e as lésbicas se eles/elas fingirem que são heterossexuais. $\mathrm{O}$ racismo cordial e a homofobia cordial são expressões de uma realidade social em que a convivência se dá não pelo reconhecimento das diferenças, mas pela negação das mesmas. E, ao juntar dois termos que nasceram para viver separados (cordialidade \& racismo; cordialidade \& homofobia), tento compreender como é possível existir uma cultura política baseada na violência e na exclusão, ao mesmo tempo em que performatiza a cordialidade a ponto de termos numa comunidade uma senhora que infantiliza, castiga os internos, colocando-os em situações limites de dor e ainda assim ser chamada de "tia".

Há outro tipo de sujeitos que não são aceitos socialmente, mesmo que tentem dissimular suas diferenças. Eles não podem circular e devem ocupar espaços apropriados para seus corpos 
impróprios. E impróprio aqui tem o sentido de não pertencimento ao campo de inteligibilidade humana, de serem vidas nuas (Agamben, 2004).

Enquanto eu lia a emocionante e densa etnografia de Pereira, lembrava das pessoas trans (travestis, transexuais, transgêneros, cross-dressing) no Brasil. Da mesma forma que os internos da Fraternidade, seus corpos trazem marcas que as colocam fora de qualquer nível de convívio ou de circulação socialmente aceitável.

Conforme sugeri em outro momento (Bento, 2011), muitas vezes utilizamos a noção de abjeção para significar um considerável campo de exclusão social, dotando-o de uma plasticidade interpretativa que me parece equivocada. $\mathrm{O}$ que provoca nojo? Quais corpos não têm um léxico para nomear suas experiências? A vida dos internos da comunidade Fraternidade $e$ as exclusões das pessoas trans nos falam de corpos que apresentam determinados atributos, os quais os conceitos, os nomes, a própria linguagem não alcançam. Como disse Riobaldo, "muita coisa importante falta nome" (Rosa, 2012:109).

Qual a forma possível de serem "aceitos"? Abrindo mão completamente de qualquer agência, entregando-se aos mandos e as infantilizações das instituições. No caso das pessoas trans isso tem uma dramaticidade singular. $\mathrm{O}$ que essa experiência nos revela é o desejo encarnado da agência humana. Com isso não estou afirmando que não existam pessoas trans que reforçam as normas de gênero, mas a própria existência de pessoas que vivem o gênero tencionando os limites discursivos na naturalização das expressões de gênero, em si já marca um ponto de confronto com as normas de gênero. No entanto, para tentar conseguir alguns direitos (como, por exemplo, as cirurgias de transgenitalização e as mudanças nos documentos do nome e sexo), devem abrir mão de uma arma poderosa, a agência, e se conformar com o discurso da patologização. 


\section{O dispositivo experimental em ação}

A neutralidade científica tem sido um recurso discursivo para legitimar e diferenciar as ciências de outras formas de saber. A singularidade e a superioridade da ciência estariam nos procedimentos utilizados para descobrir a verdade que terá validade universal. A observação sistemática, os procedimentos de controle, registro e mensuração são recursos que marcariam essa singularidade. Essa suposta singularidade será questionada por Isabelle Stengers (2002) que conferirá à invenção do dispositivo experimental a singularidade do fazer científico.

Por dispositivo experimental a autora entende os mecanismos acionados pelos cientistas no espaço laboratorial $e$ fora dele para que suas invenções sejam validadas pela comunidade científica. Ele só faz existir um "fato" na medida em que mobiliza aliados e aciona um conjunto de ações da obtenção de recursos à circulação de uma descoberta. A ciência é, nesse sentido, um processo de bricolagem e negociação. Para fazer existir um fato, é preciso ampliar a rede de aliados que o sustenta.

$\mathrm{O}$ dispositivo experimental interpreta o cientista como ator que atua motivado pelo convencimento a outros atores, tanto dentro quanto fora do laboratório. No entanto, a dimensão política do fazer ciência é invisibilizada. Tudo aparece como se a molécula estivesse ali, parada, no espaço controlado do laboratório, esperando para ser decifrada, ou que bastaria o cientista ter um poderoso arsenal teórico-metodológico de coleta de dados que a verdade seria revelada. Stengers (2002) dirá que de nada valeria a descoberta se o cientista não acionasse os outros campos sociais para, de fato, dar vida a sua invenção. Nesse sentido, não há diferença entre as ciências exatas, biomédicas e humanas. Somos impelidos a fazer política. Não existe verdade sem convencimento.

Outro desdobramento da ciência como ficção/política está na dimensão ética. No momento em que o cientista faz o trabalho de convencimento tem que se confrontar com os valores que circulam na sociedade. E quando a descoberta começa a fazer sua 
trajetória, suas travessias, terá que se confrontar com diferentes noções de verdade, de morte, de vida.

Ao ler o livro de Pedro Paulo, o suposto fetiche da objetividade/neutralidade do dispositivo experimental torna-se insustentável. No capítulo Nas tramas de um debate somos levados a entender o funcionamento desse dispositivo de forma nua, mediante o debate entre pesquisadores sobre a existência ou não da aids. Divididos em dois campos (que Pereira nomeia de pesquisadores oficiais $e$ "dissidentes da aids"), os pesquisadores enredam disputas discursivas brutais. De um lado, os dissidentes afirmam que a terapia oficial $e$ a adesão ao tratamento oficial são mortais (administração dos antirretrovirais) e nunca se provou a existência da aids. A saída para uma vida saudável, aponta o grupo, seria hábitos saudáveis. Do outro lado, pesquisadores oficiais deslegitimam completamente a fala dos dissidentes $e$ qualifica-os de "loucos".

A pesquisa de Pedro Paulo é instigante porque não há uma leitura binária ou maniqueísta da contenda, o que a diferencia de outras pesquisas que discutem o saber/poder médico. Seu objetivo foi apontar como as partes estruturam discursos para disputar uma concepção de verdade, uma vez que ambas estão no campo científico e nenhuma das partes abre mão da objetividade de suas afirmações. E a partir daí, o autor nos coloca diante de disputas de proporções gigantescas, que envolvem diretamente um continente inteiro (a África), organizações internacionais, interesses comerciais da indústria farmacêutica, ativismos de diversas posições e regiões do mundo. São múltiplos acontecimentos experimentais (Stengers, 2002) que são postos em cena com efeitos diversos, a exemplo do protagonismo que assumiu o presidente da África do Sul, Thabo Mbeki, ao se pronunciar publicamente sobre a possível confusão entre os sintomas da aids e da miséria $e$ por suspeitar tanto do valor dos antirretrovirais quanto o HIV como causa da aids.

$\mathrm{O}$ debate entre os oficiais $e$ os dissidentes me remeteu a uma conversa que tive com uma mulher branca da classe média alta paulista e HIV positivo. Eu tinha acabado de ler a tese de 
Pedro Rossi (2012) e estava impactada com a história de vida de uma de suas colaboradoras, uma mulher pobre, negra e HIV positivo. A sua luta para viver era diária. Em cada passagem, eu escutava a voz de Riobaldo: "Viver é muito perigoso" (Rosa, 2012:49). E no quadro de miserabilidade apresentado, a aids parecia ser o fato de menor importância em sua vida e a própria adesão ao tratamento muitas vezes era secundarizada. A mulher de classe média escutava com atenção. No entanto, quando lhe disse que a colaboradora da pesquisa de Rossi já tinha passado fome muitas vezes, ela me interrompeu: "Eu duvido que alguém passe fome em São Paulo. Talvez em outro estado, mas aqui, eu duvido". Eu inferi que ela estava sugerindo que a mulher negra e pobre era preguiçosa e vitimista.

Para as duas mulheres parecia que (concordando com as posições "dos dissidentes da aids") a aids era o que menos impactava suas vidas. Também fui levada a acreditar que o "mantra" repetido pelo grupo ("o que mata é a falta de qualidade de vida”), fazia sentido. A mulher de classe média tinha qualidade de vida. A pobre, lutava diariamente pela vida. O "mantra" fica sem eficácia se não cruzarmos os marcadores da diferença (Brah, 2006) que configuram subjetividades e contextos sociais singulares e podem resvalar para um moralismo com prescrições comportamentais, conforme aponta Pedro Paulo ao interpretar os discursos dos dissidentes. E aí uma visão colonizadora dos corpos (que não são contextualizados) pode ser um dos pontos de unidade entre os oficiais e os dissidentes.

\section{...Eu quase que nada não sei. Mas desconfio de muita coisa. (Rosa, 2012:15)}

O que fazer quando uma profissional da saúde vê vida em um corpo e a aldeia, através do seu xamã, já diagnosticou a morte? O que é morte? O debate em torno dos significados da vida e da morte estão presente nos capítulos Limites, traduções e afetos. $\mathrm{O}$ autor analisa com sensibilidade e profundidade os dilemas de uma enfermeira dedicada ao trabalho com a saúde 
indígena. Diante do diagnóstico do xamã da morte da criança e o início dos rituais em torno do corpo, a enfermeira começou um longo trabalho de convencimento do xamã de que ainda tinha vida naquele corpo. O confronto entre duas cosmovisões é um dos momentos mais dramáticos do livro. Muitas vezes, a sensação que me atravessava era que eu estava diante de um conto literário, tamanha a capacidade do autor em nos aprisionar em sua narrativa e compartilhar os dramas dos seus personagens.

Depois de muita conversa, a jovem enfermeira convenceu o xamã da importância de levar a criança para o serviço médico onde seriam realizados os procedimentos necessários para ressuscitá-la. A mãe, o xamã, o avô (cacique da aldeia), a criança $e$ a enfermeira entram na canoa e atravessam o rio. A cada momento, o xamã perguntava para a enfermeira: "E aí, ela já morreu?"

Essa história é relatada a Pedro Paulo pela jovem enfermeira. Admito, contudo, que fiquei com uma vontade imensa de conversar com a mãe e o xamã. O que eles viam no corpo da criança que o idioma científico da profissional de saúde não alcançava? Em nossa sociedade a pessoa é considerada morta quando o médico profere palavras que vão mudar uma determinada realidade (Austin, 1990);uma sentença mágica que cria uma nova realidade: seu parente veio a óbito. Antes desse momento, não há morte. Mas essa sentença, a verdade da verdade, a morte como fim de tudo, está envolta em dúvidas.

David Sudnow (1967) realizou uma etnografia em dois hospitais nos Estados Unidos. Seu objetivo era compreender as práticas de inspeção, exame, disposição, anunciação, preparação do corpo, autópsia, a organização do necrotério e as regras de certificação da morte no espaço hospitalar. Enfim, como os acontecimentos biológicos são reconhecidos, nomeados e tratados por uma complexa organização social que se vê, muitas vezes, empurrada contra a parede para definir o que é morte.

Sudnow (1967) argumenta que a separação dos elementos sociais e biológicos para determinação da morte é de difícil alcance. Para o médico, o biólogo, ou físico-químico, a conclusão 
de que uma pessoa está morta ou morrendo não são inteiramente claras. Em certos ciclos médicos há considerável desacordo sobre o preciso significado da morte biológica. Alguns argumentam que seria o fim da atividade celular, outros insistem que é necessária maior atenção às propriedades de multiplicação das células. No ambiente hospitalar se maneja, geralmente, três níveis de morte: a clínica, a biológica e a social (o paciente é tratado basicamente como um cadáver, embora clinicamente possa ter sinais vitais).

Nos marcos dos múltiplos significados e sinais de que a vida não existe mais no corpo, Sudnow (1967) relata o caso de uma médica que gastou vários minutos tentando dar um suco para um paciente e ele teimosamente se recusava. A enfermeira, afinal, lhe disse que paciente estava morto.

Para além das explicações (e disputas) científicas em torno da morte/vida, o que se pode inferir é que o hospital, lugar da verdade científica por excelência, onde há uma linguagem própria e um idioma quase secreto é compartilhado entre os iniciados nas universidades, é antes de tudo um espaço mágico. O que seriam o diagnóstico e o prognóstico? São profecias baseadas na ritualização do otimismo e do pessimismo (Christakis, 1999). Há muito de xamã no médico e há muito de médico no xamã.

Mesmo no espaço impessoal e burocratizado, a morte exige seus rituais. Acredito ser um equívoco afirmar que não há rituais em torno da morte nas instituições hospitalares. Quando anunciar a morte, como anunciar, para quem anunciar os preparativos do corpo, tudo se repete de forma estruturante e estrutural. Com isso não estou afirmando que os atos que performatizam a morte aconteçam da mesma forma para todos os mortos. Sudnow (1967) observou como no espaço neutro e científico do hospital havia uma hierarquia da dor entre os/as médicos/as, os/as enfermeiros/as e outros/as profissionais. Algumas mortes produziam maior comoção (crianças, mulheres grávidas) que outras (suicídio, viciado em narcóticos, conhecidas prostitutas, vagabundos). Há outras, ausentes na etnografia de Sudnow, que estão fora dos rituais. São "as sucatas do mundo" (Pereira, 
2014:12), a exemplo dos internos da comunidade Fraternidade pesquisada por Pereira.

\section{Um livro indisciplinado}

De corpos e travessias: uma antropologia de corpos e afetos não é um livro exclusivo para antropólogos/as, embora o autor, ao final dos capítulos faça afirmações diretamente para seu campo disciplinar, como por exemplo: “(...) A antropologia pode tentar possibilitar que a dor do outro possa ser sentida noutros corpos. Não se trata de falar por, mas de compartilhar a fala, ou a impossibilidade dela, e de fazer com que outros participem dessa experiência" (Pereira, 2014:51).

O livro está no mundo. E minha leitura-travessia me diz que esse livro não se limita a um campo disciplinar. Precisaríamos nos apropriar da tese dos estudos transviados (ou teoria queer) de que a identidade não é fixa, para lermos nosso próprio fazer científico. Para que serve demandar o reconhecimento como pertencente a uma identidade profissional? Disputas de mercado? Reserva de mercado? Produção de pedigrees acadêmicos? Talvez o meu pensamento seja míope por não conseguir enxergar as fronteiras entre o fazer do/a sociólogo/a, do/a antropólogo/a, do/a filósofo/a, do/a historiador/a. Vejo tudo borrado. Não sei onde começa $e$ termina cada um desses campos disciplinares. As teorias que Pedro Paulo articula, os recortes temáticos, o fazer etnográfico, o debate sobre subjetividade do pesquisador/autor, a dimensão ética, atravessam diversos campos do conhecimento.

Há algum tempo eu tive uma conversa com uma colega antropóloga. Eu lhe perguntava o que me diferenciava (sou doutora em sociologia) dela (doutora em antropologia), uma vez que estávamos discutindo teorias feministas, orientando trabalhos de tese e dissertação com referências teóricas bastante próximas. É claro que o mundo acadêmico não se resume a esse campo de debates: há os comitês, os arranjos institucionais múltiplos, os editais, os concursos, as parcerias internacionais... Enfim, os dispositivos experimentais. 
Poderíamos brincar com a história bíblica que diz que deus criou o mundo e junto vieram duas maldições: o trabalho (para os homens) $e$ as dores do parto (para as mulheres). Diria que temos a nossa própria maldição: se inventou a ciência e no seu ventre veio sua negação, os campos disciplinares. Concordo com Elias (1994) que os malefícios da especialização das ciências são mais profundos que os benefícios.

A experiência da leitura do livro de Pedro Paulo é uma travessia, uma aventura, no sentido de que as respostas não são óbvias, tampouco fáceis. É preciso calma, paciência e valentia para compartilhar histórias como as de Luiz, um homem HIV positivo que se cortava e espalhava seu sangue em seu próprio corpo para afastar a polícia medrosa.

São histórias que nos mostra uma verdade já sabida: apesar de tudo, viver é extraordinário (Lispector, 1993:26). A micropolítica (Foucault, 2002) dos corpos resistindo, lutando, tem como seu corolário a micro felicidade, a exemplo de Cida, a filósofa-travesti. Daí a centralidade da categoria agência em todo o livro. A experiência do encontro com essas histórias e com os dilemas teóricos encarnados nos corpos e almas de sujeitos que teimam em viver, nos releva a nossa própria incompletude, ou, nas palavras do Riobaldo: "O senhor... Mire veja: o mais importante e bonito, do mundo, é isto: que as pessoas não estão sempre iguais, ainda não foram terminadas - mas que elas vão sempre mudando" (Rosa, 2012:23).

\section{Referências bibliográficas}

AgAmBen, G. Homo sacer: o poder soberano e a vida nua. Belo Horizonte, Editora UFMG, 2004.

Austin, J. L. Quando dizer é fazer: palauras e ação. Porto Alegre, Artes Médicas, 1990. 
BENTO, Berenice. Política da diferença: feminismos e transexualidades. In: Colling, Leandro (org.). Stonewall $40+$ o que no Brasil? Salvador, EdUFBA, 2011, pp.79-110.

BENTO, Berenice. A (re)invenção do corpo: sexualidade e gênero na experiência transexual. Rio de Janeiro, Garamond, 2006.

BíBLIA Sagrada. [http://www.bibliaonline.com.br/acf/gn - acesso em: 26 maio 2014].

BRAH, Avtar. Diferença, diversidade, diferenciação. Cadernos Pagu (26), Campinas, Núcleo de Estudos de Gêbero-Pagu/Unicamp, 2006 [http://www.scielo.br/pdf/cpa/n26/30396.pdf - acesso em: 24 abr 2014).

Christakis, Nicholas A., Death Foretold: Prophecy and Prognosis in Medical Care. University of Chicago Press, 1999.

DAVID, Macey. Frantz Fanon: a biography. London, Verso, 2000.

ELIAS, Norbert. A sociedade dos indivíduos. Rio de Janeiro, Jorge Zahar Editor, 1994.

FouCAUlt, M. Microfísica do poder. Rio de Janeiro, Editora Graal, 2002.

Hegel, GWF. Fenomenologia do espírito. Petrópolis, Vozes, 2005.

HeIDDEGGER, Martin. Ser e Tempo. Petrópolis, Vozes, 2002.

HolandA, Sérgio Buarque de. Raízes do Brasil. Rio de Janeiro, Cia das Letras, 2009.

LISPECTOR, Clarice. Uma aprendizagem ou o livro dos prazeres, Rio de Janeiro, Editora Rocco Ltda., 1998.

MuÑOZ, José Esteban. Disidentifications: queers of color and the performance of politics. Minneapolis, University of Minnesota, 1999.

PRECIADO, B. Testo Yonqui. Madrid, Espasa, 2008.

RABINOW, P. Antropologia da Razão. Rio de Janeiro, Relume-Dumará, 2002.

RosA, João Guimarães. Grande sertão: Veredas. Rio de Janeiro, Editora Nova Fronteira, 2012. 
566 Escutar vozes e falar em línguas

ROSSI, Pedro Santo. Aids e adesão à vida: seguindo uma rede de pessoas vivendo com HIV. Tese de doutorado - Saúde Coletiva, São Paulo, UNIFESP, 2012.

STENGERS, Isabelle. A invenção das ciências modernas. Rio de Janeiro, Editora 34, 2002.

SuDNOw, David. Passing on: The Social Organization of Dying. Prentice Hall, 1967. 